\title{
The role of topical simvastatin on bone regeneration: A systematic review
}

\author{
Javier Montero ${ }^{1}$, Guillermo Manzano ${ }^{2}$, Alberto Albaladejo ${ }^{3}$
}

${ }^{1}$ DDS. PhD, Tenured lecturer in Prosthodontics. Department of Surgery, Faculty of Medicine, University of Salamanca (USAL), Salamanca, Spain

${ }^{2}$ DDS, Postgraduate Student. Master in Dental Sciences. University of Salamanca (USAL), Salamanca, Spain

${ }^{3}$ DDS. PhD, Tenured lecturer in Orthodontics. Department of Surgery, Faculty of Medicine, University of Salamanca (USAL), Salamanca, Spain

\section{Correspondence:}

Clínica Odontológica. Facultad de Medicina,

C/ Alfonso X el Sabio S/N.

Campus Miguel de Unamuno.

C.P: 37007. Salamanca. Spain

javimont@usal.es

Received: 10/12/2013

Accepted: 04/03/2014
Montero J, Manzano G, Albaladejo A. The role of topical simvastatin on bone regeneration: A systematic review. J Clin Exp Dent. 2014;6(3):e28690.

http://www.medicinaoral.com/odo/volumenes/v6i3/jcedv6i3pi.pdf

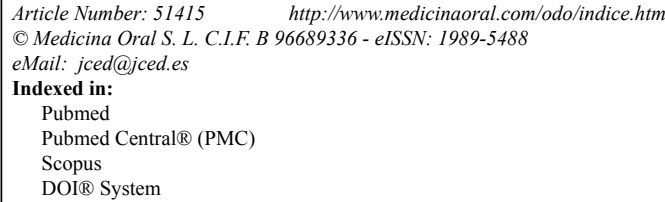

\begin{abstract}
Objectives: The aim of this systematic review was to summarize the results concerning the use of simvastatin for promoting bone regeneration and to discuss the level of scientific evidence supporting such findings.

Material and Methods: A Pubmed search using "Simvastatin"[Mesh] AND "Bone Regeneration"[Mesh] as Boolean operators was constrained to the last 10 years and only included papers written in English.

Results: Of the 41 relevant papers reviewed, most of them (76.2\%) have been published in the last 5 years, and most of them address animal studies $(66.6 \%)$ performed on rats or rabbits in extraoral regions. Only 4 randomized controlled trials (RCTs) assessed the role of topical simvastatin in periodontal patients.

Conclusions: A large part of the evidence concerning the role of topical simvastatin on bone regeneration comes from animal studies (mainly rats) focusing on extraoral bone defects. Only the use of subgingival simvastatin after root scaling has been properly supported by RCT.
\end{abstract}

Key words: Simvastatin, bone regeneration, topical administration, osteogenesis, osteoinduction.

\section{Introduction}

Since the popularization of dental implants, clinicians have found themselves in circumstances in which they are forced to place implants in areas where the quality, quantity and topography of bone substrate are clearly unfavorable. In addition, several regenerative strategies have been proposed with the aim of preserving the alveolar process after tooth extraction (1) or for augmenting bone support for dental implants (2). Thus, the demand for effective biomaterials for bone augmentation procedures is currently increasing owing to the disadvantages of using autogenous bone graft material, such as limited bone availability, additional morbidity at the donor site, the impossibility of storage, and the need for general anesthesia for extraoral donor sites (3). In light of this, researchers are now searching for bone graft materials with improved osteogenic properties, with the advantages of autologous bone grafts [osteogenesis, osteoinduction and osteoconduction], but without their disadvantages [donor site morbidity, difficulty of storage and maintenance, unlimited availability, etc.]. 
Alloplastic bone substitutes have been combined with different molecules for the efficient induction of bone formation. In 1965, Urist used hydrochloric acid for the demineralization of bone matrix and observed ectopic bone formation after the implantation of demineralized bone matrix within the soft tissues, calling this process bone formation by autoinduction (4). It was not until 1980 that the same author reported the identification in the rat organic bone matrix of an insoluble protein of low molecular weight called Bone Morphogenetic Protein [BMP] (5). However, the use of BMPs entails some problems such as their short life, storage and handling difficulties, inefficiency in the recognition of target cells, and high cost. This has hampered their popularization in bone regeneration procedures (6).

On searching for alternatives to the application of these exogenous genetically engineered proteins, some authors have suggested the topical use of drug compounds aimed at upregulating intrinsic bone growth factors. For example, some widely known pharmacologic compounds [such as bisphosphonates or statins] have recently been shown to upregulate bone growth through distinct and complex biochemical pathways $(7,8)$. Along this line, in 1999 Mundy et al. (9) were the first authors to report that lovastatin and simvastatin stimulate bone regeneration when injected subcutaneously in mouse calvaria. Since then, a huge development of research focusing on clinical applications has occurred in traumatology (10), oral surgery (11), and periodontology (12).

Simvastatin is one of the most commonly prescribed drugs for the treatment of hypercholesterolemia because it prevents the synthesis of cholesterol (13). In addition to its lipid-lowering effects, simvastatin can also elicit some pleiotropic effects, leading to the modulation of the process of bone regeneration at the molecular and cellular levels (14). Simvastatin seems to play an important role in bone regeneration by participating directly in osteoblast activation [increasing BMP-2 expression] and in osteoclast inhibition (15), and also indirectly, by stimulating neovascularization [increasing the secretion of Vascular Endothelial Growth Factor] (16).

The biological feasibility and the biochemical pathways of topical simvastatin in bone regeneration have been reviewed recently (14), but the current level of evidence concerning regenerative applications of simvastatin has not been established in a systematic way.

\section{Objectives}

The aim of this systematic review was to summarize the results on the use of simvastatin for promoting bone regeneration and to discuss the level of scientific evidence supporting such findings.

\section{Material and Methods}

In October 2013, we made a search in Pubmed using as keywords simvastatin and bone regeneration, obtaining 75 results. In addition, to limit the search results we used the following search strategy: "Simvastatin" [Mesh] and "Bone Regeneration" [Mesh], constraining the search to papers written only in English and published in the last 10 years obtaining 37 relevant hits. This search was complemented with a manual search of 4 relevant articles cited among the previously selected papers. The 41 papers were revised in depth, and their main findings have been summarized throughout the result and discussion sections, discussing current knowledge and noting future trends based on the level of evidence. The distribution of such 41 revised papers according to the date of publication and the study design is shown in Table 1.

\section{Results}

Regarding study design (Table 1), it is to be noted that most of the revised papers [76.2\%] have been published in the last 5 years, most of them involving animal studies [66.6\%] performed on rats or rabbits in extraoral regions. To date, only one research team led by Pradeep has carried out 4 well-performed randomized clinical trials demonstrating that locally- administered simvastatin, versus placebo, significantly improves the clinical outcomes of scaling and root planing for treating mandibular buccal Class II furcation defects (17) and in patients with chronic periodontitis (18), even when they are smokers (19) or suffer from type 2 diabetes (20).

The in vitro studies have reported that simvastatin seems to stimulate bone formation significantly (21) and also aids in periodontal regeneration (22).

Studies focusing on pharmacological development have tested several biodegradable polymeric formulas for the local delivery of simvastatin, which is water-insoluble, such as a hydrogel of gelatin (23) or microspheres of poly-lactide-co-glycolide (24), although some carriers tested also seem to be able to release several bone-forming biomolecules simultaneously (25).

Regarding animal studies, it should be noted that most of them have been carried out in extraoral regions of rats (Table 1) (26-33). The large majority of these studies reported favorable results concerning topical application of simvastatin, either injected alone (31) or in combination with biomaterials (28), or for coating implants (26) or covering acellular scaffolds (32). However, this osteogenic effect has also been observed when simvastatin was administered systemically by means of a $5 \mathrm{mg} / \mathrm{kg}$ daily intraperitoneal (30) or oral dose (33).

In addition, most animal studies performed intraorally have reported good results for topical simvastatin administration in enhancing bone regeneration in rat mandibular defects (34) and periodontal lesions in rats [7,35], Beagles (36) and minipigs (37).

Nevertheless, other authors have reported unfavourable results after using simvastatin for bone formation. Pauly 
Table 1. Distribution of the reviewed papers according to the study design $(\mathrm{n}=41)$.

\begin{tabular}{|c|c|c|c|c|c|c|c|c|c|c|}
\hline \multirow[t]{3}{*}{ Period } & \multirow{3}{*}{$\begin{array}{l}\text { Articles } \\
\mathbf{N}(\%)\end{array}$} & \multirow{3}{*}{$\begin{array}{l}\text { In Vitro } \\
\text { Studies }\end{array}$} & \multirow{3}{*}{$\begin{array}{l}\text { Pharmacological } \\
\text { development }\end{array}$} & \multicolumn{6}{|c|}{ ANIMAL STUDIES } & \multirow[t]{3}{*}{ RCT } \\
\hline & & & & \multicolumn{2}{|l|}{ Rats } & \multicolumn{2}{|l|}{ Rabbits } & \multicolumn{2}{|c|}{ Dogs/minipigs } & \\
\hline & & & & Intraoral & Extraoral & Intraoral & Extraoral & Intraoral & Extraoral & \\
\hline $2008-2013$ & $32(76.2)$ & $3(7.3)$ & $3(7.3)$ & $3(7.3)$ & $10(24.4)$ & $1(2.4)$ & $4(9.8)$ & $3(7.3)$ & $1(2.4)$ & $4(9.8)$ \\
\hline $2002-2007$ & $9(23.8)$ & 0 & $2(4.9)$ & $2(4.9)$ & $3(7.3)$ & 0 & $2(4.9)$ & 0 & 0 & 0 \\
\hline TOTAL & $41(100.0)$ & $3(7.3)$ & $5(12.2)$ & $5(12.2)$ & $13(31.7)$ & $1(2.4)$ & $6(14.6)$ & $3(7.3)$ & $1(2.4)$ & $4(9.8)$ \\
\hline
\end{tabular}

et al. (27) reported impaired integration of intramedulary titanium implants coated with simvastatin after 8 weeks of healing in rat femurs. In the same sense, Lima et al. (38) found a negative impact of combining simvastatin with demineralized bovine bone matrix for repairing calvarial defects in rats after 30 to 60 days of healing. In agreement with these studies on rats, in other studies performed on rabbits the authors failed to find any clear improvement on using topical simvastatin in osteoinductive activity for the short-term repair of nasal bone defects (15) or for enhancing mandibular distraction, even when applied both locally during the osteotomy phase, and systemically during the distraction osteogenesis period (11). Anbinder et al. also found that simvastatin administration, either orally or subcutaneously, did not improve bone repair for experimental tibial defects in rats (39). Rutledge et al. reported only minor effects of locally injected simvastatin for inducing new bone formation in the jaw bone of dogs (40).

\section{Discussion}

Autologous bone is still the current gold-standard graft material for the treatment of bone defects (2). However, the need for a second surgical site, the limited supply of bone available, and the impossibility of storage have led to the development of different alternative bone substitutes. These biomaterials have also been combined with different bioactive agents as an appealing cost-effective way to promote bone formation. Statins [lovastatin, fluvastatin and simvastatin] have been demonstrated to modulate bone growth when applied locally (14). However, both clinicians and researchers are still in need of an updated evidence-based review of such promising regenerative applications in the field. This study summarizes the main findings of the investigations in which simvastatin was used to stimulate bone regeneration, and, to our knowledge, is the first systematic review addressing this topic. We focused only on simvastatin, since it is the statin most widely applied for this purpose, although other statins have also been investigated.

In light of our summarized results, the use of topical simvastatin for bone regeneration can be seen as a relatively recent research line, since most studies have been carried out in the last 5 years. The majority of the studies reviewed here were performed on small mammals [mainly rats but also rabbits], and generally in ex- traoral regions, reporting mainly favourable results for several bone surgical procedures. This shows that this research line is still in its initial stages. It should be taken into account that the different rates of bone turn-over in mammals, and throughout the bones of a given species, would hamper the extrapolation of such findings to the human mouth. Nevertheless 4 RCT were found with the search strategy used here. The fact that such well-designed trials were all performed at the same centre [Government Dental College and Research Institute of Bangalore, India] and by the same research team led by Pradeep could be a cause of concern. Those authors demonstrated a significant improvement in the clinical and radiographic parameters when a flowable gel of simvastatin $[1.2 \mathrm{mg} / 0.1 \mathrm{ml}]$ was injected at sites treated by scaling and root planing among different profiles of periodontal patients (17-20). Unfortunately no other promising application drawn from animal studies, such as the use of topical simvastatin for coating implants, or bone substitutes or acellular scaffolds, has been addressed in clinical trials. Therefore, the above data should encourage researchers and clinicians to replicate the formulation of the methylcellulose-based simvastatin gel described by Pradeep et al. (17-20) in order to check clinical outcomes in other settings or applications. It seems relatively simple to randomize and mask this intervention by a placebo gel, and it would not be very difficult to access the active principle since it is commercialized. Caution should be exercised regarding the dosing of the simvastatin, since several authors have reported a dose-dependent inflammatory response (28). In animal studies, a $0.1-0.5 \mathrm{mg}$ dose of simvastatin would be the optimal dose for stimulating maximum bone regeneration without inducing inflammation (37). According to Pradeep et al. (17-20), for humans the topical dose of simvastatin did not produce any complications or adverse reactions. Regarding the carrier used by Pradeep et $a l$, methylcellulose was probably chosen for operational reasons [it is extensively used as a sustained-released vehicle for therapeutic formulations]; however, other polymeric carriers could also offer some advantages, such as a slower release of the molecules, or even multiple drug carriers (23-25).

Future efforts should be directed towards understanding the biological mechanisms underlying why a single topical application of simvastatin in a subgingival environment is able to act as an anti-inflammatory and 
regenerative agent of periodontal-tissues 6 to 9 months later, presumably affording a long-term effect (17-20). In light of several contradictory reports, it also remains unclear whether the oral consumption of statins has any significant effect on bone regeneration and periodontal health.

Long-term, multicenter, randomized, controlled clinical trials will be required to properly assess the effect of topical simvastatin in bone regeneration for many different indications.

\section{Conclusions}

Most of the evidence regarding the role of topical simvastatin on bone regeneration, comes from animal studies [mainly rats], focusing on extraoral bone defects. However 4 well-designed RCT have reported significantly better clinical outcomes when a flowable gel of simvastatin $[1.2 \mathrm{mg} / 0.1 \mathrm{ml}]$ was injected at sites treated previously with scaling and root planing in periodontal patients. No other application has been properly assessed in humans.

\section{References}

1. Araújo MG, Lindhe J. Dimensional ridge alterations following tooth extraction. An experimental study in the dog. J Clin Periodontol. 2005;32:212-8.

2. Esposito M, Grusovin MG, Coulthard P, Worthington HV. The efficacy of various boneaugmentation procedures for dental implants: a Cochrane systematic review of randomized controlled clinical trials. Int J Oral Maxillofac Implants. 2006;21:696-710.

3. Swan MC, Goodacre TE. Morbidity at the iliac crest donor site following bone grafting of the cleft alveolus. Br J Oral Maxillofac Surg. 2006;44:129-33.

4. Urist MR. Bone: formation by autoinduction. Science. 1965;150:893-9.

5. Urist MR, DeLange RJ, Finerman GA. Bone cell differentiation and growth factors. Science. 1983;220:680-6.

6. Boyne PJ, Salina S, Nakamura A, Audia F, Shabahang S. Bone regeneration using rhBMP-2 induction in hemimandibulectomy type defects of elderly sub-human primates. Cell Tissue Bank. 2006;7:110.

7. Killeen AC, Rakes PA, Schmid MJ, Zhang Y, Narayana N, Marx DB, et al. Impact of local and systemic alendronate on simvastatin-induced new bone around periodontal defects. J Periodontol. 2012;83:1463-71.

8. Srisubut S, Teerakapong A, Vattraphodes T, Taweechaisupapong S. Effect of local delivery of alendronate on bone formation in bioactive glass grafting in rats. Oral Surg Oral Med Oral Pathol Oral Radiol Endod. 2007;104:e11-6.

9. Mundy G, Garrett R, Harris S, Chan J, Chen D, Rossini G, et al. Stimulation of bone formation in vitro and in rodents by statins. Science. 1999;286:1946-9.

10. Namazi H. Effects of simvastatin on osseointegration in a canine total hip arthroplasty model an experimental study: a novel molecular mechanism. J Arthroplasty. 2012;27:162-3.

11. Kiliç E, Ozeç I, Yeler H, Korkmaz A, Ayas B, Gümüş C. Effects of simvastatin on mandibular distraction osteogenesis. J Oral Maxillofac Surg. 2008;66:2233-8.

12. Grover HS, Luthra S, Maroo S, Maroo N. The pleotropic role of statins: Could it be the imminent host modulation agent in periodontics? Dent Res. J 2013;10:143-8.

13. Jadhav SB, Jain GK. Statins and osteoporosis: new role for old drugs. J Pharm Pharmacol. 2006;58:3-18.
14. Park JB. The use of simvastatin in bone regeneration. Med Oral Patol Oral Cir Bucal. 2009;14:e485-8.

15. Alam S, Ueki K, Nakagawa K, Marukawa K, Hashiba Y, Yamamoto $\mathrm{E}$, et al. Statin-induced bone morphogenetic protein (BMP) 2 expression during bone regeneration: an immunohistochemical study. Oral Surg Oral Med Oral Pathol Oral Radiol Endod. 2009; 107:22-9.

16. Sonobe M, Hattori K, Tomita N, Yoshikawa T, Aoki H, Takakura $\mathrm{Y}$, et al. Stimulatory effects of statins on bone marrow-derived mesenchymal stem cells. Study of a new therapeutic agent for fracture. Biomed Mater Eng. 2005;15:261-7.

17. Pradeep AR, Priyanka N, Kalra N, Naik SB, Singh SP, Martande S. Clinical efficacy of subgingivally delivered $1.2-\mathrm{mg}$ simvastatin in the treatment of individuals with Class II furcation defects: a randomized controlled clinical trial. J Periodontol. 2012;83:1472-9.

18. Pradeep AR, Thorat MS. Clinical effect of subgingivally delivered simvastatin in the treatment of patients with chronic periodontitis: a randomized clinical trial. J Periodontol. 2010;81:214-22.

19. Rao NS, Pradeep AR, Bajaj P, Kumari M, Naik SB. Simvastatin local drug delivery in smokers with chronic periodontitis: a randomized controlled clinical trial. Aust Dent J. 2013;58:156-62.

20. Pradeep AR, Rao NS, Bajaj P, Kumari M. Efficacy of subgingivally delivered simvastatin in the treatment of patients with type 2 diabetes and chronic periodontitis: a randomized double-masked controlled clinical trial. J Periodontol. 2013;84:24-31.

21. Bae MS, Yang DH, Lee JB, Heo DN, Kwon YD, Youn IC, et al. Photo-cured hyaluronic acid-based hydrogels containing simvastatin as a bone tissue regeneration scaffold. Biomaterials. 2011;32:816171.

22. Liu S, Bertl K, Sun H, Liu ZH, Andrukhov O, Rausch-Fan X. Effect of simvastatin on the osteogenetic behavior of alveolar osteoblasts and periodontal ligament cells. Hum Cell. 2012;25:29-35.

23. Tanigo T, Takaoka R, Tabata Y. Sustained release of water-insoluble simvastatin from biodegradable hydrogel augments bone regeneration. J Control Release. 2010;143:201-6.

24. Nath SD, Son S, Sadiasa A, Min YK, Lee BT. Preparation and characterization of PLGA microspheres by the electrospraying method for delivering simvastatin for bone regeneration. Int J Pharm. 2013;443:87-94.

25. Jeon JH, Puleo DA. Alternating release of different bioactive molecules from acomplexation polymer system. Biomaterials. 2008;29:3591-8.

26. Yang G, Song L, Guo C, Zhao S, Liu L, He F. Bone responses to simvastatin-loaded porous implant surfaces in an ovariectomized model. Int J Oral Maxillofac Implants. 2012;27:369-74.

27. Pauly S, Back DA, Kaeppler K, Haas NP, Schmidmaier G, Wildemann B. Influence of statins locally applied from orthopedic implants on osseous integration. BMC Musculoskelet Disord. 2012;13:208.

28. Nyan M, Miyahara T, Noritake K, Hao J, Rodriguez R, Kuroda $\mathrm{S}$, et al. Molecular and tissue responses in the healing of rat calvarial defects after local application of simvastatin combined with alpha tricalcium phosphate. J Biomed Mater Res B Appl Biomater. 2010;93:65-73.

29. Nyan M, Sato D, Kihara H, Machida T, Ohya K, Kasugai S. Effects of the combination with alpha-tricalcium phosphate and simvastatin on bone regeneration. Clin Oral Implants Res. 2009;20:280-7.

30. Ayukawa Y, Ogino Y, Moriyama Y, Atsuta I, Jinno Y, Kihara M, et al. Simvastatin enhances bone formation around titanium implants in rat tibiae. J Oral Rehabil. 2010;37:123-30.

31. Ayukawa Y, Yasukawa E, Moriyama Y, Ogino Y, Wada H, Atsuta I, et al. Local application of statin promotes bone repair through the suppression of osteoclasts and the enhancement of osteoblasts at bone-healing sites in rats. Oral Surg Oral Med Oral Pathol Oral Radiol Endod. 2009;107:336-42.

32. Pişkin E, Işoğlu IA, Bölgen N, Vargel I, Griffiths S, Cavuşoğlu T, et al. In vivo performance of simvastatin-loaded electrospun spiralwound polycaprolactone scaffolds in reconstruction of cranial bone defects in the rat model. J Biomed Mater Res A. 2009;90:1137-51. 
33. Du Z, Chen J, Yan F, Xiao Y. Effects of Simvastatin on bone healing around titanium implants in osteoporotic rats. Clin Oral Implants Res. 2009;20:145-50.

34. Junqueira JC, Mancini MN, Carvalho YR, Anbinder AL, Balducci I, Rocha RF. Effects of simvastatin on bone regeneration in the mandibles of ovariectomized rats and on blood cholesterol levels. J Oral Sci. 2002;44:117-24.

35. Maciel-Oliveira N, Bradaschia-Correa V, Arana-Chavez VE. Early alveolar bone regeneration in rats after topical administration of simvastatin. Oral Surg Oral Med Oral Pathol Oral Radiol Endod. 2011;112:170-9.

36. Morris MS, Lee Y, Lavin MT, Giannini PJ, Schmid MJ, Marx DB, et al. Injectable simvastatin in periodontal defects and alveolar ridges: pilot studies. J Periodontol. 2008;79:1465-73.

37. Chen S, Yang JY, Zhang SY, Feng L, Ren J. Effects of simvastatin gel on bone regeneration in alveolar defects in miniature pigs. Chin Med J. 2011;124:3953-8.

38. Lima CE, Calixto JC, Anbinder AL. Influence of the association between simvastatin and demineralized bovine bone matrix on bone repair in rats. Braz Oral Res. 2011;25:42-8.

39. Anbinder AL, Junqueira JC, Mancini MN, Balducci I, Rocha RF, Carvalho YR. Influence of simvastatin on bone regeneration of tibial defects and blood cholesterol level in rats. Braz Dent J. 2006; 17:267-73.

40. Rutledge J, Schieber MD, Chamberlain JM, Byarlay M, Killeen AC, Giannini PJ, et al. Simvastatin application to augment facial jaw bone in a dog model: pilot study. J Periodontol. 2011;82:597605 .

\section{Conflict of Interest}

The authors declare that they have no conflict of interest. 